\title{
Biobanking for Epidemiological Research and Public Health
}

\author{
Angela M. Brand ${ }^{a}$ Nicole M. Probst-Hensch ${ }^{b}$

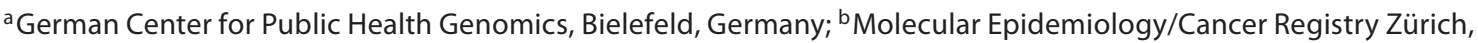 \\ University of Zürich, Zürich, Switzerland
}

\section{Key Words}

Biobanking $\cdot$ Epidemiological research $\cdot$ Genomics $\cdot$ Health policy development $\cdot$ Health services $\cdot$ Individual health information management $\cdot$ Public health $\cdot$ Surveillance systems

\begin{abstract}
Almost all healthcare systems are currently facing fundamental challenges. New ways of organizing these systems based on novel knowledge and stakeholders' different needs are required to meet these challenges at the appropriate time. In this context, the issue of biobanking has become a specific challenge having major implications for future research and policy strategies as well as for the healthcare systems in general. Medicine is currently undergoing remarkable developments from its morphological and phenotype orientation to a molecular and genotype orientation, promoting the importance of prognosis and prediction. Yet, the discussion about the relevance of integrating genomebased information into biobanks and about the role of genome-based biobanking for epidemiological research and public health is still at the beginning. The following article contributes to this discussion by focusing on the use of genome-based biobanking for epidemiological research, surveillance systems, health policy development, individual health information management and effective health services.

Copyright $\odot 2007$ S. Karger AG, Basel
\end{abstract}

\section{KARGER}

Fax +41613061234

E-Mail karger@karger.ch

www.karger.com (c) 2007 S. Karger AG, Basel

1015-2008/07/0744-0227\$23.50/0

Accessible online at:

www.karger.com/pat

\section{Introduction}

To date, epidemiological research and public health practice have focused on environmental determinants of health and disease and have paid scant attention to genomic variations within a population as well as between populations. The advances brought about by genomics are changing these perceptions $[1,2]$. Many predict that this knowledge will not only enable clinical interventions but also health promotion messages and disease prevention programs to be specifically directed and targeted at susceptible individuals as well as subgroups of the population, based on their genomic profile and risk stratification. For example, nowadays, it is known that coding variants in DNA determine not only the cause of singlegene disorders, which affect millions of people worldwide, but also predispositions ('susceptibility') [3], based on genotype and haplotype variants [4-6], to common diseases. The new technologies will allow researchers to rapidly and comprehensively investigate the whole human genome at the level of individual genes [7]. Furthermore, there will also be a better understanding of the significance of environmental factors, e.g. chemical agents, nutrition or personal behavior [8], in relation to the causation not only of diseases like osteoporosis, cardiovascular [9] and cerebrovascular diseases, cancer and diabetes, which account for $86 \%$ of all deaths and $77 \%$ of the disease burden in Europe in 2005, but also of psychiatric disorders, allergies and infectious diseases [10-12].

Prof. Dr. med. Angela Brand, MPH

German Center for Public Health Genomics, University of Applied Sciences Kurt-Schumacher-Str. 6

DE-33615 Bielefeld (Germany)

Tel. +49521 1067864 or 7865, Fax +49521 163709, E-Mail angela.brand@fh-bielefeld.de 
In the past, there had been a narrowed focus looking mainly at the role of inheritance in monogenetic diseases and genetic testing of more than 1,000 diseases in that context (human genetics setting). At present, the role of genetic susceptibilities and other biomarkers in systems biology and complex diseases is discussed (medical, community health as well as public health setting). In the future, the focus will be even broader by analyzing the role of genomic variants together with other health determinants such as social or environmental factors in health problems (public health setting).

Thus, already now, regarding the understanding of diseases, the following 'trends' due to novel genomebased knowledge and technologies can be identified:

- the potential of an earlier and more precise identification of risk strata in the population (i.e. the identification of high-, moderate- and low-risk groups; the stratification by 'genome-based standardization' in addition to age and sex standardization of diseases);

- the differentiation between disease (sub)entities resulting in the same phenotype (e.g. breast cancer), which are either following mainly a mendelian trait ('inherited') or mainly a genomic-environmental pattern;

- the concept of a genomic variant being in different individuals a risk factor or a protective factor (e.g. the role of the ACE insertion-deletion polymorphism in stroke (increased risk) and Alzheimer's disease (decreased risk) [13]);

- pleiotropic effects of susceptibility genes in complex diseases being associated with more than one disease (e.g. the role of the G-308A TNF- $\alpha$ gene variant in obesity, asthma and non-Hodgkin lymphoma [1416]): shift from disease orientation to 'risk orientation', 'disease clusters' and 'health outcomes';

- the potential of individual genomic profiling (i.e. the simultaneous evaluation of multiple susceptibility genes) as the basis for individual health information management; here, the individual genotype status on all genomic variants increases or decreases the risk for certain diseases;

- the shift from carrier screening to a screening based on individual genomic profiling;

- the role of genomic determinants not only within a bunch of other health determinants (e.g. social, behavioral, environmental or biological) but also as a modifier and triggering factor (e.g. epigenomic effects);

- the role of genomic determinants as 'necessary but not sufficient' determinants in the development of complex diseases and health problems;
- the differentiation between predictive tests (i.e. tests with $0-100 \%$ probability being a continuum and referring to monogenetic as well as to complex diseases) and tests for diseases with high penetrance (referring to monogenetic diseases as well to complex diseases following a mendelian trait) and low or moderate penetrance (most complex diseases);

- the shift in the definitions: from 'genetic test' to 'genomic variant' to 'genome-based health information'.

These trends show that, obviously, the integration of genome-based knowledge into epidemiological and public health research, policies and health services for the benefit of all will be one of the most important challenges in the future that our health care systems will face [1721].

Besides that novel knowledge, accompanying novel technologies are already triggering the shift in the comprehension of health and disease as well as in the understanding of new approaches to prevention and therapy [22-24]. For example, high-throughput technologies such as tissue microarrays (TMAs) have the potential to screen large numbers of molecular targets in tumor samples for rapid causal, prognostic, diagnostic or therapeutic purposes [25]. Complementary to the conventional microarray gene expression profiling, population-based TMAs can be implemented to quickly validate gene expression microarray data in a larger population of tissue samples. This will provide information at the microanatomical level by the use of immunohistochemistry for proteins and in situ hybridization for RNA [26]. Through population-based TMAs, it will be possible to assess multiple genomic and protein differences among malignancies, e.g. colorectal cancer, breast cancer, gliomas or rhabdomyosarcoma and thus to analyze the molecular and cytogenetic changes associated with these malignancies, including human carcinogenic infections [27].

Another example of the potential of novel genomebased technologies is the use of nanochips, which allow the detection of gene activity and genomic patterns by measuring messenger RNA (mRNA). Consequently, it will be possible to predict the response to certain therapies, e.g. interferon therapy, with higher accuracy and even quicker.

One of the key questions in all health care systems is the question whether 'the right' interventions and services are provided by the various stakeholders: Are the current public health strategies based on evidence? Are we assuring the 'right' health interventions (based on combined concepts of health need assessment and health technology assessment) in the 'right' way (based on con- 
cepts of quality management and policy impact assessment) in the 'right' order and at the 'right' time (based on concepts of priority setting and health targets) in the 'right' place (based on concepts of integrated health care and health management)?

So far, there has been almost no systematic integration of genome-based knowledge into all of these concepts. Current public health strategies are therefore lacking one important aspect of evidence-based evaluation. Thus, with regard to systems biology and genomics, the public health agenda demands a novel vision that reaches beyond the research horizon to arrive at application and public health impact assessment of this novel technology $[12,28]$.

What is the role of genome-based biobanking in that defined scenario?

\section{Genome-Based Biobanking for Epidemiological Research}

The definition of biobanking is very wide and has a twofold character comprising both samples and data. Since biobanks cover therapeutic biobanks like blood and tissue banks, including umbilical cord blood banks, semen banks as well as organ collections, they can be defined as collections of samples of human body substances (e.g. cells, tissues, blood or DNA) that are or can be associated with individual data and information such as clinical, socioeconomic, demographic, lifestyle, behavioral and environmental health determinants.

Biobanking not only allows to store probes of the human body, it also assures the standardization of sampling processes and data collection. As a result, target-orientated, preventive, diagnostic and therapeutic interventions can be developed to promote personalized medicine and health care. In the long run, this will result in the provision of more effective and efficient health services.

Furthermore, the already mentioned rapid development of biotechnological research such as populationbased TMAs as well as bioinformatics has stimulated the use of biobanks. Although it has been recognized that population-based data on genome-disease and genomeenvironment interactions are the primary point for assessing the added value of genome-based information for all health interventions in the different health care settings, this approach is not unprecedented. Human body substances of all kinds have been collected, stored and used for a variety of purposes for many years. Already in the past, large epidemiologic cohort studies such as EPIC
(European Prospective Investigation into Cancer and Nutrition), ARIC (Atherosclerosis Risk in Communities) [29], ALSPAC (Avon Longitudinal Study of Parents and Children), ISAAC (International Study of Asthma and Allergies in Childhood), EUROCAT (European Surveillance of Congenital Anomalies) or various cancer registries and neonatal screening programs (e.g. in Denmark or Western Australia) have been able to perform genotyping to expand their existing databases for studying disease incidence and prevalence, natural history and risk factors [1]. In addition, large cohort studies, e.g. in the UK [30], or even involving whole populations, e.g. in Iceland or Estonia [31], have been initiated to establish repositories of biological materials for the study and characterization of genomic variants associated with common diseases. These biobanks enable to quantify disease incidences in various populations and subpopulations as well as to understand their natural histories and risk factors, including genome-environment interactions $[32,33]$.

Nevertheless, the majority of existing biobanks are still relatively small collections of tissue samples related to specific diseases such as cancer. They have been established, for example, in university departments (e.g. in pathology clinics) or in cancer registries, and contain a few hundred up to a few thousands human biospecimens. These biobanks will remain important in the future. However, in addition large-scale population-based biobanks have to be established facilitating research not only on single diseases but also on 'disease clusters' based on pleiotropic effects of susceptibility genes in complex diseases as well as approaches of system biology to a wide range of other health-related issues.

In most countries, besides the scarcity of human biospecimens, one major bottleneck for large-scale biomedical research is the fragmentation of biorepositories. Biobanks maybe organized in different clinical settings, in the public sector or in pharmaceutical companies. Irrespective of the responsible institution for biobanking, they may be funded by public or private resources and they also may have been established and used to serve a variety of interests - for instance, purely scientific interests, the interests of donors or commercial interests.

In addition, for most common diseases, so far the collection of body samples for genome-based association studies has been retrospective in nature and often also has been limited to cases of a particularly pronounced phenotype or with a strong family history. In order to be able to evaluate the relative risk of a given genomic variant retrospectively from case-control studies, its background frequency in the sample population must be 
known. Thus, there is a need to recruit large samples of unselected controls from the populations of interest as well as to extend the common cross-sectional or retrospective ascertainment of phenotypes for the prospective follow-up of at least a subset of cases, defined for example by an incidence cohort.

This means that on the one hand long-term cohort studies - starting as early as possible in life and including nested case-control studies at various ages and at various occasions - have to be established. This will be a costly, long-lasting, but nevertheless essential public health task.

On the other hand another - less costly and less timeconsuming - public health task could be the implementation of case-control studies in the very old population to generate hypotheses on pathways of system biology, genomic-environmental associations, on epigenomic effects as well as on pleiotropic effects.

One specific biobank which has not often been recognized in most countries as an already existing nationwide genome-based biobank is newborn screening. It has been established for decades in the public sector, in private hand or in public-private partnership. Recently, not only the possibility of reanalyzing up to 25-year-old Guthrie cards has been discussed. Also very soon, there will be a discussion about shifting from newborn screening exclusively on metabolic diseases to a DNA-based newborn screening for genomic variants. A major point of societal discussion will be the question for which validated genomic variants, in addition to metabolic diseases, should newborns be tested for in the future. Should it be for complex diseases with the highest burden of disease (e.g. for cardiovascular diseases, cerebrovascular diseases, diabetes, cancer and osteoporosis accounting for $77 \%$ of the disease burden in 2005 in Europe) or for orphan diseases (accounting for $10 \%$ of all diseases in the whole population and having involved highly validated genomic variants) by developing a resequencing chip for orphan diseases?

Based on these needs, the future challenges for biobanks with respect to epidemiological research and public health are comprehensive as well as manifold. They include the promotion of public-private partnerships, the linkage of records (e.g. perinatal quality assurance programs, hospital discharge data or data from registries) with data from (genome-based) samples in addition to population-based (mega)biobanks. They also include the integration of genome-based information into the many already existing population-based surveillance systems such as into surveillance systems for infectious diseases, congenital malformations or even into health observato- ries, and the integration of genome-based knowledge into future surveillance systems covering health problems and linking individual information during the whole lifespan (record-linkage based surveillance). Thus, genome-based biobanks can be used as a basis for individual genomic profiling as well as a tool for individual health information management.

Population-based data on genome-disease associations and genome-environment interactions form the basis for studying the added value of genome-based health information in various health care settings. They will help to better understand the contribution of genomic variants to common diseases. In the meantime, there is the need to consider, at the appropriate time, how best to collect and monitor information stemming from genome-based research and technologies, to close gaps and to frame the policy development of evidence-based strategies in that field. Thus, the argument of biobanking in the context of public health surveillance systems seems to be crucial.

\section{From Epidemiological Research to Population- Based Surveillance Systems and Public Health}

So far, biobanking and surveillance systems have been looked at independently from each other. This is astonishing, since the concept of surveillance has been quite successfully developed and implemented in various fields of public health in the last decades. Considerations of problems like data protection or data sharing as well as the development of processes and methods in the context of surveillance programs could be easily translated into biobanks.

The idea of observing, recording and collecting facts, analyzing them and considering reasonable health interventions is very old and stems already from Hippocrates [34]. However, before a large-scale organized system of surveillance can be developed, certain requirements need to be fulfilled, e.g. an organized health care system, a classification system for diseases as well as appropriate diagnostic criteria.

Currently, surveillance is defined as the ongoing systematic collection, analysis and interpretation of outcome-specific data applied to design, implement and evaluate public health practice [35]. It includes the functional capacity for data collection and analysis as well as the timely dissemination of these data to persons who can undertake effective prevention and therapy. Surveillance data tell where the problems are, who is affected, and 
where effective and efficient health interventions should be directed. Such data can also be used to define public health priorities in a quantitative manner and to evaluate the effectiveness of programs. Furthermore, the analysis of surveillance data enables researchers, especially epidemiologists, to identify areas of interest for further investigation.

The application fields of surveillance systems are numerous: to quantitatively estimate the magnitude of health problems in a population at risk, analyze the natural history of diseases, assess differences by geographic areas, detect and document the spread of health events, identify research needs to facilitate epidemiologic and laboratory research, test hypotheses about the etiology of diseases, identify differences in the health status within ethnic or other subgroups of the population, evaluate health interventions such as preventive or curative strategies, monitor changes in the nature of diseases, longterm trends or changes in health practices as well as foster strategic health planning.

Especially the use of registries for surveillance and other medical or public health interventions has increased in the last few years. Registers such as cancer registries differ from other sources of surveillance data in that information from multiple sources is linked for each individual over time. Information is collected systematically from diverse sources including hospital discharge data, treatment records, pathology reports and death certificates. This specific type of registry is also suitable to monitor health events in groups with increased exposure to hazardous agents. Nevertheless, population-based registries are particularly useful for surveillance because, using incidence rates, the occurrence of a health event can be estimated over time in different geographic areas and subgroups of the population.

The availability and value of data for surveillance depend on a number of factors. These factors include the extent to which classification schemes are used to categorize diagnosis, signs, symptoms, procedures and reasons for health care, and the extent to which information for individuals from different administrative sources over time periods can be linked using a unique personal identifier, e.g. in Denmark or Western Australia. Here, the integration of genome-based biobanks and technologies such as TMAs or nanochips will be a specific challenge.

In the future, several developments are expected to contribute to the evolution of surveillance systems such as the implementation of bioinformatics, the ability to make more effective use of sophisticated epidemiological and statistical tools to detect changes in patterns of health problems, the electronic dissemination of surveillance data, and - last but not least - novel knowledge and innovations such as genome-based knowledge and technologies. The critical challenge, however, is the need to regard surveillance as a scientific enterprise. To do this properly, the principles of surveillance and their role in guiding epidemiologic research and in influencing other aspects of the overall mission of public health have to be fully understood. In addition, new epidemiological methods based on public health surveillance have to be developed. Bioinformatics for efficient data collection, analysis and dissemination have to be applied. Ethical, legal and social concerns have to be addressed right in time, the benefit of surveillance systems has to be reassessed on a routine basis, and surveillance practice has to be translated into emerging areas of public health practice such as the integration of genome-based biobanks.

The success of these surveillance systems including genome-based biobanks will heavily depend on the quality of the information in the system (i.e. on validated population-based genomic variants) and on the value of the information to its intended users. A clear understanding of how policymakers, voluntary and professional groups, researchers, the commercial sector and other stakeholders might use surveillance data is valuable in gathering the support of these audiences for the surveillance system.

Regarding data sharing it has to be stressed that different sources of information need to be accessed and compared with or added to the data collected in its own system, e.g. laboratory results, tissue results, epidemiological information for specific conditions, population estimates and mortality records. Through responsible planning and coordination on the part of managers on reporting systems, standard coding schemes can be adopted as data systems evolve. These actions, for example, have the potential to facilitate the sharing and use of data.

European and US institutions and platforms like the Public Health Genetics Unit in Cambridge, UK, the German Center for Public Health Genomics in Bielefeld, the Turkish Center for Public Health Genomics and Personalized Medicine in Ankara or the US National Office of Public Health Genomics at the Centers for Disease Control and Prevention in Atlanta, Ga., USA, who work closely together with researchers from genetic and molecular science ('modern biology') as well as from population science, humanities and social science, are optimistic and agree about the relevance of the integration of genomebased biobanks into surveillance systems and, thus, pub- 
lic health in general [36-39]. Interestingly enough, they all have strong links or are even part of the respective national genome research projects in these countries and are translating genome-based knowledge from biotechnology and biobanks through genetic epidemiology or 'classical' epidemiology' into public health ('translational research'). Using methods like horizon scanning, fact finding and monitoring to identify research trends as early as possible, they are already doing a prospective evidence-based evaluation. That is an evaluation that is already carried out in the process of basic research and not just in the (retrospective) process of the implementation of public health strategies and policies [40], which always will tend to lack behind.

\section{Public Health Ethics as a New Paradigm}

The present discussion about ethical aspects of biobanking is dominated by the conventional and individual-centered moral categories of medical ethics and bioethics. Especially in this context of biobanking, however, focusing always on individual rights and protections, e.g. informed consent, confidentiality, discrimination, stigmatization or the 'right not to know' in the end, will undermine individual rights and interests in ways that benefit some organized interests, because important social, political and scientific questions will be hardly considered [41].

Regardless of the question of whether in the situation of 'informed consent' the promises and information that potential research subjects are given are accurate, and regardless of the point that informed consent is irrelevant to many groups of potential research subjects, the biggest concern is that by focusing on individual consent to research, the importance of statutory research, e.g. epidemiological and public health research or the monitoring of the effectiveness and efficiency of specific health interventions, that poses few risks to individuals but is essential to assure and improve (collective) health care provision, is neglected. This focus on individual decision-making not only ignores contexts of choice but is also connected to a view of ethics that is separated from politics.

Moreover, if ethics in the context of biobanking is further promoting informed consent and confidentiality, then ethics is no longer concerned with the scientific validity of research, balancing likely benefits of research and establishing research priorities. Thus, the question of whose health and whose interests will be served by re- search is critical. Public policy principles such as institutional oversight and competing political priorities, ethical principles such as solidarity, justice and good governance as well as the concepts of benefit sharing and informed contract will be able to provide an appropriate public health ethics framework [42-44]. However, continuing to make an artificial division between ethical and political aspects, on the one hand, and between individual rights and public goods, on the other hand, will impede any innovative future use of biobanking.

Since policy development in the field of biobanking must take contextual as well as cultural factors into consideration, "both collective and individual rights and interests are at stake in creating or assessing genomic databases for public health research' [45]. At the same time, a public health ethics framework $[44,46]$ must be based on norms beyond the legal and ethical criteria of autonomy and privacy.

Also, since biobanks require an ongoing contribution from the potential research subjects, if not samples, then at least health information and possible lifestyle data need to be collected over an indefinite period of time. It becomes obvious that in this situation it is not possible to render data completely anonymous, as this would prevent new data being linked to the old, and to tissue samples or genome-based information.

Clarifying the general conditions under which genome-based knowledge and technologies can be put to best practice in the field of biobanking, epidemiological research and public health surveillance, paying particular attention to the public health-specific ethical, legal and social implications $[36,38,47]$, is currently the most pressing task and thus has been stressed by public health genomics. The aims of genetic and molecular science being to foster health and disease prevention via the organized efforts of society, integral to its activities is the dialogue with all stakeholders in society, including industry, governments, health professionals and the general public [39].

Policymakers must be aware of the current challenge to improve consumer protection, to monitor the implications of genome-based knowledge and technologies for health, social and environmental policy goals, and to assure that genomic advances will be tailored not only to treat medical conditions, but also to prevent disease and improve health [48]. Sound and well-reflected genetic policies and programs require a timely and coordinated process for evidence-based policy making that relies on scientific research and ongoing community consultation [49]. An acceptable and maybe delicate balance between 
providing strong protection of individuals' interests [50, 51] and enabling society to benefit from the genomic advancements at the same time must be found $[36,48,52$, 53].

Interestingly enough, research in biobank-related fields, e.g. in the field of genetically modified food, has been able to distinguish between trust in governance, trust in government and trust in non-governmental organizations, since trust is an important predictor of the attitude of individuals towards innovations, public acceptance, technological optimism and various forms of behavior. Public trust as a rather complex social and political phenomenon remains an important issue in the near future, especially in the context of the integration of genome-based biobanks into public health surveillance systems. It is not just the restoring of public faith in government, industry, non-governmental organizations or other stakeholders, it is also related to the way government or politicians are willing to involve the public within decision-making, how industry is handling consumer interests, and individuals' perception of the way biotechnology may influence their lives [54]. With higher levels of trust in governance, being even more important than trust in government or non-governmental organizations, people have a more positive attitude towards an innovation, are more likely to accept new knowledge and technologies, and are more optimistic about technological developments [55]. For example, regarding the implementation of population-based biobanks, policy-makers and clinicians should attempt to narrow the gap between expectations and reality [56].

Since the effectiveness and efficiency of biobanks depend very much on people's willingness to contribute samples for both research and storage, public support is thus essential in assuring the long-term realization and the potential of biobanks. It is also based on the assumption that the complex issues surrounding biobanks are managed appropriately by the responsible authorities. Although the majority of the general public is willing to donate a sample to a biobank [57], the willingness is mainly driven by altruism, and depends on the public being well informed and having trust in experts and institutions. In general, there is an overwhelming positive attitude towards genomic research. Nevertheless, the trust in the capability of authorities to evaluate the chances and risks of genomic research varies, whereas individual university/hospital-based researchers receive the greatest trust, while health care providers and the politicians receive the lowest trust. Most individuals (86\%) would donate a linked blood sample for research purposes and would also agree to both donation and storage (78\%). Besides, the most common motive is the benefit of future patients $(89 \%)$ as well as the benefit for themselves or their families (61\%). Those more likely to donate a sample are middle aged and have children, which may be explained by the theory about generativity [58], have a genetic disease in the family or among close friends, are blood donors, have a positive attitude towards genomic research and have high trust in experts and institutions. Only $1 \%$ refuse to allow their tissue to be used for commercial research. Consequently, maintaining or improving the public's trust seems to be as important as having an informed public.

Independent from the ethical points mentioned above, it should be allowed to argue that at present 'reinventing the wheel' seems to be very true in the discussion around biobanks.

Almost all ethical and legal aspects which have been discussed so far in detail in the context of biobanking, and especially in the context of genome-based biobanking, are neither new nor exceptional. Already for several years, there has been a rich and growing body of literature on ethical issues in epidemiological research and public health practice including conceptual frameworks of public health ethics. Attention has been given to issues such as generalizable knowledge by elucidating the causes of disease, by combining epidemiological data with information from other disciplines such as genomics and microbiology, by evaluating the consistency of epidemiologic data with etiological hypotheses and by providing the basis for developing and evaluating health promotion and prevention procedures [59]. Ethics guidelines have been developed, e.g. for the Industrial Epidemiology Forum, the International Society for Environmental Epidemiology and the American College of Epidemiology. The latter discusses core values, duties and virtues in epidemiology, the professional role of epidemiologists, minimizing risks and protecting welfare of research participants, providing benefits, ensuring an equitable distribution of risks and benefits, protecting confidentiality and privacy, obtaining informed consent, submitting proposed studies for ethical review, maintaining public trust, avoiding conflicts of interest and partiality, communicating ethical requirements, and confronting unacceptable conduct and obligations to communities.

Thus, the benefit of public health surveillance must be balanced against possible risks and harms, such as infringements on personal privacy. There is also the need to balance health as a value with values of privacy and autonomy. Above all, there is a need for sensitivity of eth- 
nic and cultural habits and norms. Such concerns have been addressed through participatory community-based research.

The interest in ethical issues in epidemiological research and public health reflects both the important societal role of public health and the growing public interest in the scientific integrity of health information as well as the fair distribution of health care resources [59, $60]$.

\section{Best Practices of Biobanking for Epidemiological Research and Public Health}

Neither any single large cohort study nor any other single epidemiological population-based study will have adequate statistical power to examine all potentially relevant genomic variants, their interactions with each other and with environmental factors, gene expression profiles and proteomic patterns. Thus, national and international collaboration is essential to realize the full potential of biobanks and other large-scale population studies and also to develop and apply standardized epidemiological methods for assessing genomic variants in populations by means of systematic reviews, training and dissemination of information. A few important examples of such collaborations are described below.

\section{Surveillance, Epidemiology and End Result Registry}

The US Surveillance, Epidemiology and End Results (SEER) Registry is probably the largest population-based registry in the western world, currently covering $26 \%$ of the US population (www.seer.cancer.gov/). It collects information from specific population-based cancer registries since 1973 aiming to estimate cancer-related incidence and mortality, to identify unexpected changes in the incidence of specific types of cancer over time, to estimate patient survival with respect to the type of cancer, extent of disease, therapy and demographic, socioeconomic as well as other parameters of prognosis, and to foster studies of cancer risk/protective factors, screening and prognostic factors to promote target-oriented intervention. In the SEER program, for example, incidence rates for cancer are published regularly, and descriptive analysis of cancer incidence rates by age, sex, gender and geographic area are routinely performed.

Thus, SEER offers tremendous research potential beyond traditional surveillance activities. Since SEER has been expanded to a population-based tissue bank providing an unbiased sampling framework to evaluate the pub- lic health impact of genomics and proteomics that may be used for preventive, diagnostic or therapeutic purposes in defined populations, it may serve as a keystone of molecular epidemiology studies in cancer. Clinical outcome data, for example, can be correlated with validated prognostic markers, and using TMAs it will be possible to assess multiple genetic and protein differences among tumors.

\section{Public Population Project in Genomics}

The Public Population Project in Genomics $\left(P^{3} G\right)$ is an international, not-for-profit organization for the development and management of a multidisciplinary infrastructure in the field of population genomics (www. p3gconsortium.org). $\mathrm{P}^{3} \mathrm{G}$ will enable the international research community to deliver more effective health care strategies aimed at disease prevention and at tailoring treatment regimens according to the individual, family and community.

Dedicated to fostering collaboration between researchers and projects in the field of population genomics, $\mathrm{P}^{3} \mathrm{G}$ develops, in an open and transparent manner, research tools for effective collaboration between biobanks in order to enable the international research community to share expertise and resources and facilitate knowledge transfer for the health of populations.

The aims of $\mathrm{P}^{3} \mathrm{G}$ aims are to

- create a network in population genomics that will comprise over 3 million participants in epidemiological studies;

- provide statistical power for analyzing complex genetic and environmental determinants of health and disease;

- leverage the combined expertise of hundreds of researchers around the world;

- promote communication among national and international organizations;

- increase the ability to share and generate new knowledge dedicated to improve public health and welfare. Major issues need to be addressed prior to transferring new genetic discoveries to health care systems. These issues range from the essential step of validating initial findings in other populations, to understanding genetics in relation to diseases. Other issues such as the impact of the environment, the cost implications of genetic testing in relation to benefits for populations and their governments, and the establishment of appropriate guidelines to inform health ministries, health care workers, patients and their relatives also need to be addressed. 


\section{Western Australian Genome Health Project}

The Western Australian (WA) Genome Health Project is in the process of developing a national and international resource for genetic epidemiology that will build on the unique WA population health data collected and managed over the last 3 decades (www.populationhealth. uwa.edu.au/welcome/research/dlu/linkage). These data are based on linkage within and between the WA statutory collections (all births, deaths, hospitalizations, mental health services contacts and cancer registrations) and additional population disease registers and health surveys. These linkages mean that the entire WA population can be monitored for all major diseases/conditions, their risk and protective factors, and the use and role of health services studied. The core datasets now include all birth cohorts since 1980 (including prospective antenatal and perinatal data on all live births in the State) as well as the linkage of hospitalizations and disease registries commenced in the 1970s. Recent additional linkages have combined data on national medicare and pharmaceutical benefits as well as aged care from the Health Insurance Commission and Commonwealth Department of Health and Aged Care, enabling the study of all hospital and medical service contacts for particular diseases and conditions. No other state in Australia and very few countries have this capacity, which has been responsible for a large number of epidemiological advances. A number of internationally unique, population-based disease registries are linked to the core datasets, e.g. mental health, type-1 diabetes, cerebral palsy, birth defects and cancer. Stage 1 of the Family Connections Project has recently linked nuclear families within the core WA total-populationbased databases back to the early 1970s using electronic registrations, and is now extending the pedigree linkages back to 1840 , using paper records and public assistance (stages 2 and 3 ). In addition to the core datasets in the WA Data Linkage System, there are a large number of diseasefocused clinical and epidemiological research populations that have been collected in WA over the last 30 years along with a large number of biospecimen banks. A substantial proportion of these datasets and biospecimen banks are population-based datasets. The WA Genetic Epidemiology Resource is currently enabling the integration of all extant and future disease-specific clinical, epidemiological and genetic resources available in WA with biospecimen banks and with the WA Data Linkage System. The linkage of the core population-based datasets to a large number of longitudinal cohort studies with extensive exposure data and biospecimens means that there will be the potential to investigate the changing roles of

Biobanking for Epidemiological Research and Public Health genes, environment, and gene-gene and gene-environment interactions over the entire life span in populationbased samples representative of the general Australian population. A WA Genome Health Project is currently planned and will ultimately aim to collect detailed health data and biospecimens from all consenting members of the living population of WA (about 2 million people). A critical component of these initiatives is the Genomics, Society and Human Health Program to address ethical, legal and social implications and to undertake community outreach. The vision for genetic epidemiology in WA mandates the ultimate involvement of the entire WA community, and a large part of the effort is directed at the community outreach necessary to engage and inform all sectors of the society about genetic epidemiology. Together with the unique WA population-based health records, a WA Genome Health Project will establish the premier resource for human genetic research in the world in Australia, and will ensure Australia takes an international leadership role in human genetics, biotechnology and pharmaceutical development. It was intended to pilot this study in 2006 (www.jfhs.org.au) and to actively pursue harmonization with other large biobank projects internationally.

\section{Public Health Genomics European Network}

Considering genomic variants as a factor contributing to health and as such as a component for public health, genomic determinants recently played an eminent role in a new EU health strategy. To create sound genome-based policies and programs, public health will be involved and moreover take the lead by applying the three core functions of public health (assessment, policy development and assurance) to the provision of not only genetic health care services but also all other health care services, e.g. the integration of genome-based biobanks into surveillance systems.

The European Commission had in its report on 'Life Sciences and Biotechnology' [COM(2004) 250, April 7th 2004] committed itself to increase 'cooperation and exchange of information in order to enhance coherence and disseminate best practice'. Furthermore, in the work plan 2005 of the 'community action in the field of public health' the European Commission called for an application for a 'networking exercise ... to lead to an inventory report on genetic determinants relevant to public health. This network will identify public health issues linked to current national practices in applying genetic testing and on that basis will contribute to developing best practice in applying genetic testing.' 
Thus, in the beginning of 2006, the Public Health Genomics European Network (PHGEN) has been funded by the European Union (www.phgen.nrw.de; EU Project No. 2005313), which is coordinated by the Institute of Public Health North Rhine-Westphalia in Bielefeld, Germany. Associated partners are the Public Health Genetics Foundation in Cambridge, UK, as well as the German Center for Public Health Genomics at the University of Applied Sciences in Bielefeld, Germany. PHGEN involves experts as collaborating partners from the fields of public health and epidemiology, human genetics and molecular biology, social sciences, (public health) ethics, medicine, economics, political sciences and (European) law. From all EU member states, applicant countries and countries of the European Free Trade Association and European Environment Agency, at least a representative from public health and genetics as well as a relevant competent authority are included. Furthermore, representatives of other European networks (e.g. EuroGentest, Orphanet, EUnetHTA, PHOEBE or NuGO) as well as representatives of relevant initiatives and institutions at the European and international level, e.g. WHO, WTO, OECD, STOA, AETMIS, the National Office of Public Health Genomics at the Centers for Disease Control and Prevention, GRaPHInt, HumGen, the Turkish Center for Public Health Genomics and Personalized Medicine or the UK DNA Banking Network are involved to ensure complementarity and promote synergies [61]. In the long run, PHGEN will serve the European Commission as an 'early detection unit' for horizon scanning, fact finding and monitoring of the integration of genome-based knowledge and technologies into public health. Using this network, scientific advances can probably be timely, effectively, efficiently and socially acceptably translated into evidence-based policies and interventions that improve population health all over Europe.

\section{Conclusion}

New genome-based information and technologies will force health communities to enhance (i) surveillance systems by integrating the knowledge derived from biobanks and (ii) epidemiologic capacity for collecting and analyzing information stemming from communitybased assessments of genomic variation [62], providing evidence about the burdens of various diseases. Similar to other fast-paced scientific and technological advancements, the intersection between genomics and public policy will continue to require close monitoring using public health methods like health technology assessment [6368], health need assessment as well as health impact assessment and will also continue to require timely action. Consequently, there will be a chance to ensure the appropriate and responsible use of genome-based information and new technologies [69].

The various stakeholders in public health play a key role in translating the implications of genome-based research arriving from biobanks for the benefit of population health. In setting the epidemiological research agen$\mathrm{da}$, in balancing individual and social concerns, by promoting meaningful communication about genomics among researchers, professionals, public health agencies and the public, '... public health organizations will enhance the potential return on public investment in genomic research' [70].

This will be a doable project [71], but will require regional, European as well as global coordination [72]. The next decade will provide a legal window of opportunity (see forthcoming European IPTS report on data protection and biobanking prepared by Ibarreta, Zika and Schulte in den Bäumen) to establish infrastructures (across Europe and globally) that will enable the scientific advances to be effectively and efficiently translated into evidence-based policies and interventions that improve population health [73]. Policymakers now have the opportunity to protect consumers, to monitor the implications of genomics for health services and to assure that genomic advances will be taped to prevent disease and improve health [74].

\section{Acknowledgment}

This article is a result of the work of PHGEN, which is funded within the Public Health Program of the European Commission (Project No. 2005313). Nevertheless, the views described reflect the views of both authors.

References

1 Peltonen L, McKusick VA: Genomics and medicine. Dissecting human disease in the postgenomic era. Science 2001;291:12241229.

2 Khoury MJ: Relationship between medical genetics and public health: changing the paradigm of disease prevention and the definition of a genetic disease. Am J Med Gen 1997; 17:289-291.

3 Baird PA: Identification of genetic susceptibility to common diseases: the case for regulation. Perspect Biol Med 2000;45:516-528. 
-4 Lai E, Bansal A, Hughes A: Medical applications of haplotype-based SNP maps: learning to walk before we run. Nat Gen 2002;32:353.

5 Gibbs RA, Belmont JW, Hardenbol P: The International HapMap Project. Nature 2003; 426:789-796.

-6 Probst-Hensch NM, Ingles SA, Diep AT, Haile RW, Stanczyk FZ, Kolonel LN, Henderson BE: Aromatase and breast cancer susceptibility. Endocr Relat Cancer 1999;6:165-173.

7 Guttmacher AE, Collins FS: Genomic medicine - a primer. N Engl J Med 2002;347: 1512-1521.

8 Antonovsky A: Unraveling the Mystery of Health. How People Manage Stress and Stay Well. San Francisco, Bass, 1987.

-9 Sing CF, Stengard JH, Kardia SL: Genes, environment, and cardiovascular disease. $\mathrm{Ar}$ terioscler Thromb Vasc Biol 2003;23:1950.

10 Dorman JS, Mattison DR: Epidemiology, molecular biology and public health; in Khoury MJ, Burke W, Thomson EJ (eds): Genetics and Public Health in the 21st Century. Using Genetic Information to Improve Health and Prevent Disease. New York, Oxford University Press, 2000, pp 103-121.

11 Little J: Reporting and review of the human genome epidemiology studies; in Khoury MJ, Little J, Burke W (eds): Human Genome Epidemiology. A Scientific Foundation for Using Genetic Information to Improve Health and Prevent Disease. New York, Oxford University Press, 2004, pp 168-192.

12 Brand A, Brand H: Public health genetics challenging 'public health at the crossroads'. Ital J Publ Health 2005;2:59.

-13 Lehmann DJ, Cortina-Borja M, Warden DR, Smith D, Sleegens K, Prince JA, van Duijn CM, Kehoe PG: Large meta-analysis establishes the ACE insertion-deletion polymorphism as a marker of Alzheimer's disease. Am J Epidemiol 2005;162:305-317.

14 Sookoian SC, Gonzalez C, Pirola CJ: Metaanalysis on the G-308A tumor necrosis factor alpha gene variant and phenotypes associated with the metabolic syndrome. Obes Res 2005;13:2122-2131.

15 Gao J, Shan G, Sun B, Thompson PJ, Gao X: Association between polymorphism of tumour necrosis factor alpha-308 gene promoter and astma: a meta-analysis. Thorax 2006;61:466-471.

16 Rothman N, Skibola CF, Wang SS, Morgan G, Lan Q, Smith MT, Spinelli JJ, Willett E, De Sanjose S, Cocco P, Berndt SI, Brennan P, Brooks-Wilson A, Wacholder S, Becker N, Hartge P, Zheng T, Roman E, Holly EA, Boffetta P, Armstrong B, Cozen W, Linet M, Bosch FX, Ennas MG, Holford TR, Gallagher RP, Rollinson S, Bracci PM, Cerhan JR, Whitby D, Moore PS, Leaderer B, Lai A, Spink C, Davis S, Bosch R, Scarpa A, Zhang Y, Severson RK, Yeager M, Chanock S, Nieters A: Genetic variation in TNF and IL10 and risk of non-Hodgkin lymphoma: a report from the InterLymph Consortium. Lancet Oncol 2006;7:27-38.
17 Collins FS, Patrinos A, Jordan E, Chakravarti A, Gesteland R, Walters L: New Goals for the U.S. Genome Project: 1998-2003. Science 1998;282:682-689.

18 Childs B, Valle D: Genetics, biology and disease. Annu Rev Genomics Hum Genet 2000; $1: 1-19$.

19 Collins FS, McKusick VA: Implications of the Human Genome Project for medical science. JAMA 2001;285:540-544.

20 Burke W: Genomics as a probe for disease biology. N Engl J Med 2003;349:969-974.

21 Ellsworth DL, O’Donnell CJ: Emerging genomic technologies and analytic methods for population- and clinic-based research; in Khoury MJ, Little J, Burke W (eds): Human Genome Epidemiology. A Scientific Foundation for Using Genetic Information to Improve Health and Prevent Disease. New York, Oxford University Press, 2004, pp 1737.

22 Khoury MJ: From genes to public health: the applications of genetic technology in disease prevention. Genetics Working Group. Am J Public Health 1996;86:1717-1722.

-23 Brand A: Prädiktive Gentests - Paradigmenwechsel für Prävention und Gesundheitsversorgung? Gesundheitswesen 2002;64:224229.

24 French ME, Moore JB: Harnessing Genetics to Prevent Disease and Promote Health. Washington, Partnership for Prevention, 2003

25 Torhorst J, Bucher C, Kononen J, Haas P, Zuber M, Köchli OR, Mross F, Dieterich $\mathrm{H}$, Moch H, Mihatsch M, Kallioniemi OP, Sauter G: Tissue microarrays for rapid linking of molecular changes to clinical endpoints. Am J Pathol 2001;159:2249-2256.

26 Hoos A, Urist MJ, Stojadinovic A, Mastorides S, Dudas ME, Leung DHY, Kuo D, Brennan MF, Lewis JJ, Cordon-Cardo C: Validation of tissue microarrays for immunohistochemical profiling of cancer specimens using the example of human fibroplastic tumors. Am J Pathol 2001;158: 1245-1251.

27 Kononen J, Bubendorf L, Kallioniemi A, Barlund M, Schraml P, Leighton S, Torhorst J, Mihatsch MJ, Sauter G, Kallioniemi OP: Tissue microarrays for high-throughput molecular profiling of tumor specimens. Nat Med 1998;4:844-847.

28 Yoon PW: Public health impact of genetic tests at the end of the 20th century. Genet Med 2001;3:405-410.

29 ARIC Investigators: The Atherosclerosis Risk in Communities (ARIC) Study: design and objectives. Am J Epidemiol 1989;129: 687-702.

30 Wright AF, Carothers AD, Campbell H: Gene-environment interactions - the BioBank UK study. Pharmacogenomics J 2002; 2:75-82.

31 Hakonarson H, Gulcher JR, Stefansson K: deCODE genetics, Inc. Pharmacogenomics 2003;4:209-215.
32 Khoury MJ, Millikan R, Little J, Gwinn M: The emergence of epidemiology in the genomics age. Int J Epidemiol 2004;33:936944.

33 Khoury MJ, Little J, Burke W: Human genome epidemiology: scope and strategies; in Khoury MJ, Little J, Burke W (eds): Human Genome Epidemiology. New York, Oxford University Press, 2004, pp 3-16.

34 Eylenbosch WJ, Noah ND: Historical aspects; in Eylenbosch WJ, Noah ND (eds): Surveillance in Health and Disease. Oxford, Oxford University Press, 1988, pp 3-8.

35 Langmuir AD: The surveillance of communicable diseases of national importance. $\mathrm{N}$ Engl J Med 1963;268:182-192.

36 Brand A, Dabrock P, Paul N, Schröder P: Gesundheitssicherung im Zeitalter der Genomforschung - Diskussion, Aktivitäten und Institutionalisierung von Public Health Genetics in Deutschland. Gutachten zur Bio- und Gentechnologie. Berlin, FriedrichEbert-Stiftung, 2004.

37 Khoury MJ, Burke W, Thomson E: Genetics in public health: a framework for the integration of human genetics into public health practice; in Khoury MJ, Burke W, Thomson EJ (eds): Genetics and Public Health in the 21st Century. Using Genetic Information to Improve Health and Prevent Disease. New York, Oxford University Press, 2000, pp 3 23.

38 Zimmern R, Cook C: Genetics and Health. Policy Issues for Genetic Science and Their Implications for Health and Health Services. The Nuffield Trust Genetics Scenario Project. London, Nuffield Trust, 2000.

39 Omenn GS: Public health genetics: an emerging interdisciplinary field for the post-genomic era. Annu Rev Public Health 2000;21: 1-13.

40 Walt G: Health Policy: An Introduction to Process and Power. London, Zed Books, 1994.

41 Williams G: Bioethics and large-scale biobanking: individualistic ethics and collective projects. Genomics, Soc Policy 2005;1: $50-66$.

42 Schröder P: Public Health Ethik in Abgrenzung zur Medizinethik. Bundesgesundheitsblatt 2007;50:103-111.

43 Schröder P: Gendiagnostische Gerechtigkeit. Eine ethische Studie über die Herausforderungen postnataler genetischer Prädiktion. Münster, LIT, 2004.

44 Sass HM: A 'contract model' for genetic research and health care for individuals and families. Eubios J Asian Internat Bioethics 2001;11:130-132.

45 Knoppers BM: Of genomics and public health: building public 'goods'? CMAJ 2005; 173:1185-1186

46 Coughlin S: Ethical issues in epidemiologic research and public health practice. Emerg Themes Epidemiol 2006;3:16 (http://www. ete-online.com/content/3/1/16). 
47 Michigan Center for Genomics \& Public Health. Ethical, legal and social issues in public health genetics (PHELSI), 2004. http://www.sph.umich.edu/genomics/media/subpage_autogen/PHELSI.pdf.

48 Beskow LM, Khoury MJ, Baker TG, Thrasher JF: The integration of genomics into public health research, policy and practice in the United States. Community Genet 2001;4:211.

-49 Frankish CJ, Kwan B, Ratner PA, Higgins JW, Larsen C: Challenges of citizen participation in regional health authorities. Soc Sci Med 2002;54:1471-1480.

50 O'Neill O: Autonomy and Trust in Bioethics. Cambridge, Cambridge University Press, 2002.

51 Geier M, Schröder P: The concept of human dignity in biomedical law; in Sándor J, den Exter AP (eds): Frontiers of European Health Law: A Multidisciplinary Approach. Delft, Erasmus University Press-DocVision, 2003 pp 146-182.

52 Tauber AI: Sick autonomy. Perspect Biol Med 2003;46:484-495.

53 UNESCO. International Declaration on $\mathrm{Hu}$ man Genetic Data. Paris, UNESCO, 2003.

54 Hansen L, Gutteling JM, Lagerwerf L, Bartels J, Roeterdink W: In the Margins of the Public Debate on 'Food and Genes': Research under Commission of the Committee Biotechnology and Food. Enschede, Twente University, 2001.

55 Gutteling J, Hanssen L, van der Veer N, Seydel E: Trust in governance and acceptance of genetically modified food in The Netherlands. Publ Understand Sci 2006;15:103112.
56 Coulter A, Jenkinson C: European patients' views on the responsiveness of health systems and healthcare providers. Eur J Public Health 2005; 15:355-360.

57 Kettis-Lindblad A, Ring L, Viberth E, Hansson MG: Genetic research and donation of tissue samples to biobanks. What do potential sample donors in the Swedish general public think? Eur J Public Health 2005; 16 : 433-440.

58 Erikson JM, Kivnick HQ: Vital Involvement in Old Ages. New York, Norton, 1986.

59 Seigel D: Clinical trials, epidemiology, and public confidence. Stat Med 2003;22:19-25.

60 Gostin LO: Health information: reconciling personal privacy with the public good of human health. Health Care Anal 2001;9:321335.

61 Bosch X: Group ponders genomics and public health. JAMA 2006;295:1762.

62 Annas GJ: Rules for research on human genetic variation - lessons from Iceland. N Engl J Med 2000;342:1830-1833.

63 Banta HD, Luce BR: Health Care Technology and its Assessment. An International Perspective. New York, Oxford University Press, 1993.

64 Pollitt RJ, Green A, McCabe CJ, Booth A, Cooper NJ, Leonard JV, Nicholl P, Tunaley JR, Virdi NK: Neonatal screening for inborn errors of metabolism: cost, yield and outcome. Health Technol Assess 1997;1:i-iv, 1202.

65 Brand A: Health Technology Assessment als Basis einer Prioritätensetzung; in Fozouni B, Güntert B (eds): Prioritätensetzung im deutschen Gesundheitswesen. Berlin, Logos, 2002, pp 158-163.
66 Moldrup C: Medical technology assessment of the ethical, social, and legal implications of pharmacogenomics. A research proposal for an internet citizen jury. Int J Technol Assess Health Care 2002;18:728-732.

67 Perleth M: Evidenzbasierte Entscheidungsunterstützung im Gesundheitswesen. Konzepte und Methoden der systematischen Bewertung medizinischer Technologien (Health Technology Assessment) in Deutschland. Berlin, Verlag für Wissenschaft und Kultur, 2003.

68 AETMIS (Agence d'évaluation des technologies et des modes d'intervention en santé). Health technology assessment in genetics and policy-making in Canada: towards a sustainable development. Montreal, AETMIS Symposium, September 11-12th, 2003.

69 Shani S, Siebzehner MI, Luxenburg O, Shemer J: Setting priorities for the adoption of health technologies on a national level the Israeli experience. Health Policy 2000; 54:169-185.

70 Gwinn M, Khoury MJ: Genomics and public health in the United States: signposts on the translation highway. Community Genet 2006;9:21-26.

71 Smith GD, Ebrahim S, Lewis S, Hansell AL, Palmer L, Burton PR: Genetic epidemiology and public health: hope, hype, and future prospects. Lancet 2005;366:1484-1498.

72 Daar AS: Top 10 biotechnologies for improving health in developing countries. Nat Genet 2002;32:229-232.

73 Brand A: Public health and genetics - dangerous combination? View-point section. Eur J Publ Health 2005;15:113-116.

74 Schulte in den Bäumen T: Governance in genomics. Ital J Public Health 2006;4: $46-52$. 